\title{
DOENÇA DE CAMURATI-ENGELMANN: RELATO DE CASO COM ACOMETIMENTO ÓSSEO GRAVE*
}

\author{
Alexandre Calabria da Fonte ${ }^{1}$, Carlos Marcelo Gonçalves ${ }^{2}$, Julian Catalan ${ }^{1}$, Reinaldo Ottero \\ Justino Junior ${ }^{1}$
}

\begin{abstract}
Resumo Neste artigo é descrito um caso da doença de Camurati-Engelmann em um paciente do sexo masculino, com 32 anos de idade, que foi submetido a avaliação radiológica por radiografias simples, cintilografia óssea e tomografia computadorizada, as quais mostraram achados clássicos dessa síndrome e alguns aspectos incomuns vistos somente em casos com acometimento ósseo grave.

Unitermos: Doença de Camurati-Engelmann; Displasia diafisária progressiva.
\end{abstract}

Abstract Camurati-Engelmann disease: a case report of a patient with severe bone involvement.

We report a case of Camurati-Engelmann disease in a 32-year-old male patient. This patient was submitted to radiological evaluation including plain X-rays, bone scintigraphy and computed tomography, which showed typical findings of this syndrome and uncommon aspects seen only in cases of severe bone involvement. Key words: Camurati-Engelmann disease; Progressive diaphyseal dysplasia.

\section{INTRODUÇÃO}

A doença de Camurati-Engelmann, também conhecida como displasia diafisária progressiva (DDP), é uma síndrome genética autossômica dominante rara, com penetrância altamente variável. Em grande parte dos casos há história familiar da doença, porém casos esporádicos já foram observados $^{(\mathbf{1})}$. A principal característica dessa doença é a formação óssea progressiva endosteal e periosteal, que ocorre principalmente na diáfise dos ossos longos, de forma simétrica, e determina o espessamento cortical, com estreitamento do canal medular e alargamento diafisário ${ }^{(1-3)}$.

Clinicamente, os sintomas mais freqüentes são fraqueza muscular e dor nos membros inferiores, porém alguns casos são completamente assintomáticos ${ }^{(1-3)}$. Não existe nenhum teste laboratorial específico para essa doença. O diagnóstico é firmado por meio dos achados clínico-radio$\operatorname{lógicos}^{(1,2)}$.

Neste trabalho é descrito um caso de doença de Camurati-Engelmann com acometimento ósseo grave.

* Trabalho realizado no Centro de Tratamento e Pesquisa Hospital do Câncer A.C. Camargo, São Paulo, SP.

1. Médicos Residentes de Radiologia do Hospital do Câncer A.C. Camargo.

2. Médico Radiologista do Hospital do Câncer A.C. Camargo. Endereço para correspondência: Dr. Alexandre Calabria da Fonte. Rua Professor Antônio Prudente, 211, Liberdade. São Paulo, SP, 01509-900. E-mail: acfonte@ig.com.br

Recebido para publicação em 28/1/2005. Aceito, após revisão, em 18/3/2005.

\section{RELATO DO CASO}

Paciente do sexo masculino, 32 anos de idade, pardo, com queixas de dores generalizadas pelo corpo, mais intensas em membros inferiores, há cerca de nove meses. Não havia história de casos semelhantes na família. O exame físico foi normal.

Foram realizadas radiografias simples do esqueleto, que mostraram intenso espessamento cortical, com estenose do canal medular e perda da modelagem óssea, acometendo as diáfises e metáfises dos fêmures, tíbias, fíbulas, úmeros, rádios e ulnas simetricamente (Figura 1). Também foi observada acentuada esclerose da base do crânio, calota craniana, ossos da face e arcos posteriores e processos articulares da coluna lombar. Essas alterações foram confirmadas e melhor observadas na tomografia computadorizada (Figuras 2 e 3 ). A cintilografia óssea com ${ }^{99 \mathrm{~m}} \mathrm{Tc}$ mostrou hiperconcentração heterogênea do radioindicador em calota craniana, base do crânio, região da glabela, órbitas, úmeros, rádios, fêmures e tíbias (Figura 4).

Os achados imagenológicos, associados aos aspectos clínicos e à ausência de anormalidades nos exames laboratoriais, determinaram o diagnóstico de DDP.

\section{DISCUSSÃO}

A DDP encontra-se no grupo das displasias esclerosantes por defeitos da ossi-

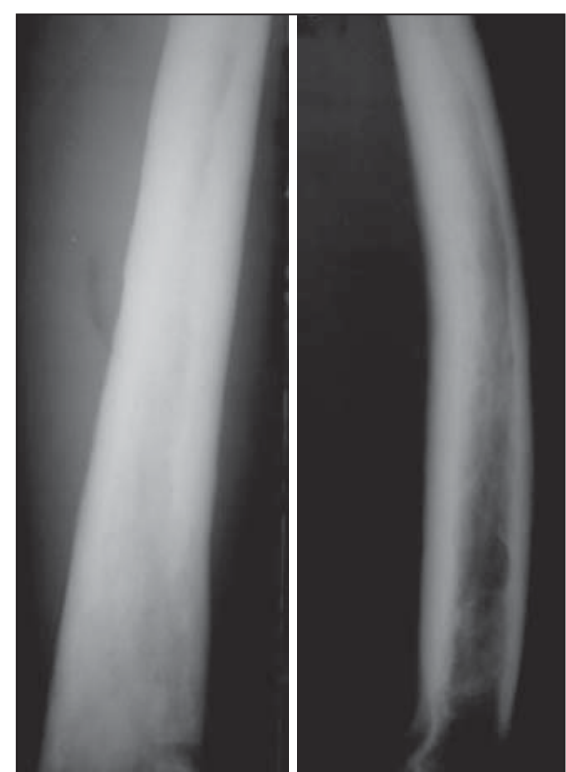

Figura 1. Radiografia do fêmur mostrando intenso espessamento cortical com estenose do canal medular e perda da modelagem óssea acometendo a diáfise e as metáfises.

ficação intramembranosa, no entanto, em alguns casos ocorre esclerose da base do crânio, que é causada por defeito da ossificação endocondral $^{(\mathbf{1 , 3})}$. Devido a isso, alguns autores especulam a possibilidade de existirem duas formas de DDP, uma pura, na qual apenas a ossificação intramembranosa é afetada, e outra mista, na qual também há um componente endocondral ${ }^{(\mathbf{1})}$.

A sua fisiopatologia ainda não é totalmente compreendida, no entanto, as alterações patológicas parecem ser causadas 

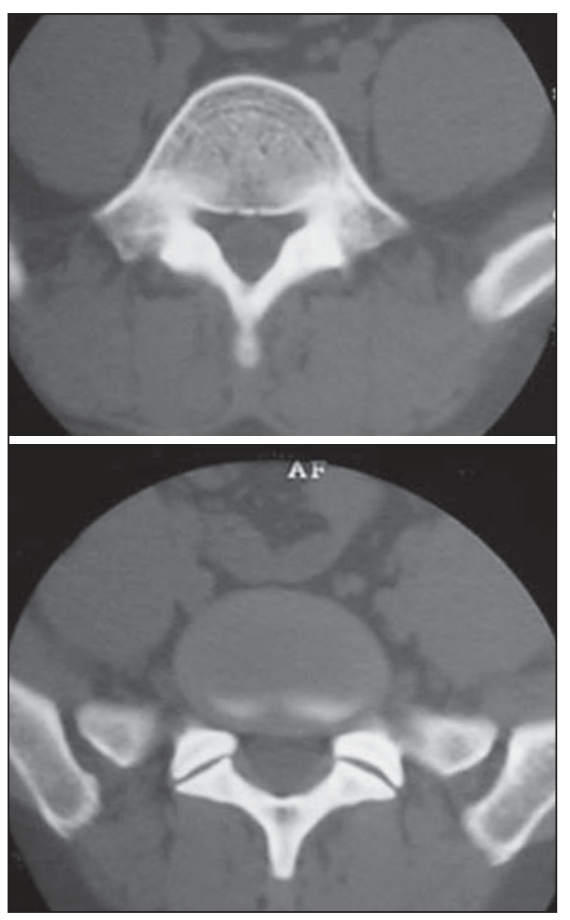

Figura 2. Tomografia computadorizada demonstrando esclerose dos arcos posteriores e apófises articulares de vértebras da coluna lombar.

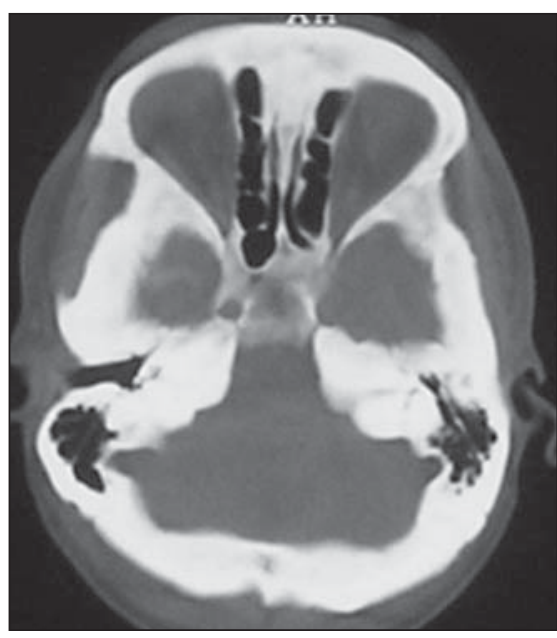

Figura 3. Tomografia computadorizada evidenciando acentuada esclerose dos ossos da base do crânio e da calota craniana.

por uma ativação inadequada da TGF $\beta 1$, que determina principalmente a redução da atividade osteoclástica, mas também promove aumento da função osteoblástica, favorecendo a deposição óssea ${ }^{(\mathbf{1}, 2)}$.

A apresentação clínica da DDP é bastante inconstante. A idade de aparecimento

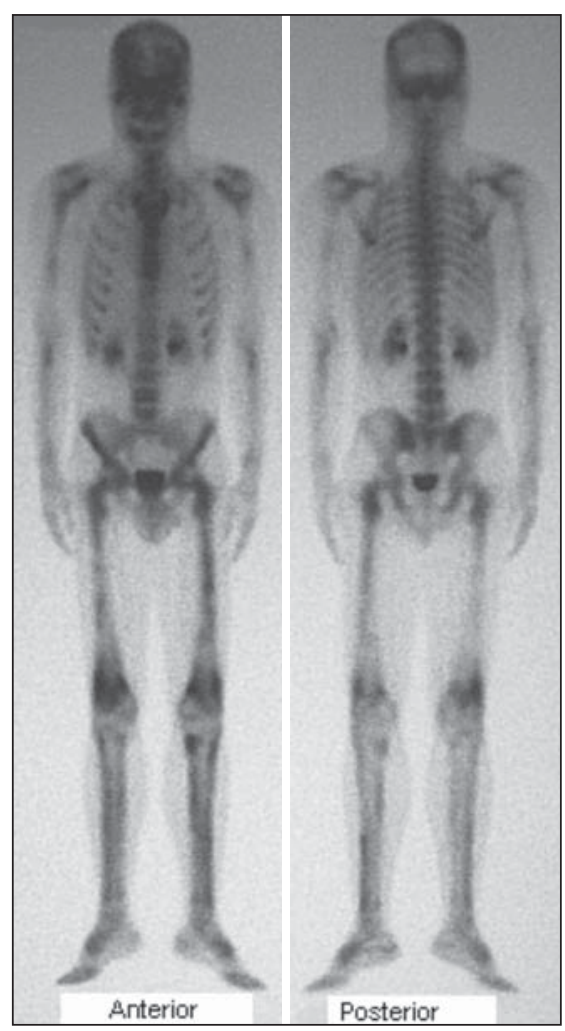

Figura 4. Cintilografia óssea demonstrando hiperconcentração heterogênea do radioindicador em calota craniana, base do crânio, região da glabela, órbitas, úmeros, rádios, fêmures e tíbias.

da doença varia de 3 meses até 50 anos de idade $^{(2)}$. Os sintomas mais freqüentemente encontrados são dores nos membros inferiores, fraqueza muscular e marcha cambaleante. Outros achados menos freqüentes incluem fadiga, atrofia muscular, fraqueza generalizada, exoftalmia, paralisia facial, dificuldade auditiva, perda da visão e puberdade retardada $^{(\mathbf{1 - 4})}$. Não há nenhuma alteração laboratorial específica.

Radiologicamente, observa-se espessamento fusiforme das corticais das diáfises dos ossos tubulares, envolvendo, em ordem decrescente de frequiência, tíbia, fêmur, fíbula, úmero, ulna e rádio ${ }^{(1-4)}$. $\mathrm{O}$ acometimento deve ser sempre simétrico e a evolução para a estenose do canal medular é uma constante ${ }^{(\mathbf{1})}$. Outros ossos podem ser acometidos ocasionalmente, como ossos da face, mandíbula, vértebras e a caixa torácica ${ }^{(\mathbf{1 , 3}, \mathbf{4})}$, estes dois últimos somente em casos de doença extremamente grave ${ }^{(3)}$.
Apesar de ser doença primariamente diafisária, a progressão metafisária já foi descrita $^{(1-3)}$ e é observada no caso relatado. A tomografia computadorizada do sistema musculoesquelético nos casos de DDP confirma com mais detalhes os achados radiográficos e demonstra a integridade da musculatura adjacente ${ }^{(\mathbf{1})}$. Na cintilografia óssea com ${ }^{99 \mathrm{~m}}$ Tc-MDP é vista captação anormal heterogênea nos ossos afetados, mesmo antes das alterações radiográficas. No entanto, a cintilografia poderá ser normal em alguns casos $^{(\mathbf{1})}$.

O diagnóstico diferencial deve ser realizado principalmente com as outras displasias causadas por defeitos na ossificação intramembranosa. As mais importantes são a displasia diafisária múltipla hereditária (doença de Ribbing) e o grupo das hiperostoses endosteais (doença de Van Buchen, doença de Worth, doença de Nakamura e doença de Truswell-Hansen $)^{(\mathbf{1 , 3})}$. Outras enfermidades que devem ser lembradas são a melorreostose, a displasia craniodiafisária, a doença de Paget, a osteopetrose, a osteoartropatia hipertrófica e a hipervitaminose $\mathrm{A}^{(\mathbf{4 , 5})}$.

Os aspectos observados nas radiografias do esqueleto, associados aos achados cintilográficos, são as bases principais para a confirmação diagnóstica da $\operatorname{DDP}^{(\mathbf{1 , 2})}$. Portanto, apesar de ser uma síndrome rara, a DDP é de importância para o radiologista, pois este desempenhará papel significativo no diagnóstico dessa doença.

\section{REFERÊNCIAS}

1. Brat HG, Hamoir X, Matthijs P, Lambin P, Van Campenhoudt M. Camurati-Engelmann disease: a late and sporadic case with metaphyseal involvement. Eur Radiol 1999;9:159-162.

2. Vanhoenacker FM, Janssens K, Van Hul W, Gershoni-Baruch R, Brik R, De Schepper AM. Camurati-Engelmann disease. Review of radioclinical features. Acta Radiol 2003;44:430-434.

3. Vanhoenacker FM, De Beuckeleer LH, Van Hul W, et al. Sclerosing bone dysplasias: genetic and radioclinical features. Eur Radiol 2000;10:1423-1433.

4. Lang WS, Viterbo BG, Kiy Y, Gérios JC, Curcelli EC. Displasia diafisária progressiva: aspectos radiológicos e cintilográficos - relato de caso. Rev Imagem 1991;13:17-19.

5. Greenspan A. Escoliose e anomalias com acometimento geral do esqueleto. In: Greenspan A, editor. Radiologia ortopédica. 3를. ed. Rio de Janeiro, RJ: Guanabara Koogan, 2000;920-924. 